\title{
Türkiye'de Yaşayan Suriyeli Mülteci Transtibial ve Transfemoral Amputelerde Protez Memnuniyetinin Değerlendirilmesi: Çok Merkezli Çalışma
}

\section{Evaluation of Prosthesis Satisfaction in Syrian Refugee Transtibial and Transfemoral Amputees Living in Turkey: A Multicenter Study}

\author{
Nilüfer Kablan ${ }^{1 *}$, Fatmagül Varol ${ }^{1}$, Yaşar $\operatorname{Tatar}^{2}$ \\ ${ }^{1}$ İstanbul Medeniyet Üniversitesi, Sağlık Bilimleri Fakültesi, Fizyoterapi ve Rehabilitasyon Bölümü, İstanbul, \\ Türkiye. \\ ${ }^{2}$ Marmara Üniversitesi, Spor Bilimleri Fakültesi, Beykoz, İstanbul, Türkiye. \\ e-mail: niluferkablan@yahoo.com, fatmagulvarol87@gmail.com, ytatar@marmara.edu.tr \\ ORCID: 0000-0002-3135-4608 \\ ORCID: 0000-0003-2808-9732 \\ ORCID: 0000-0001-6815-301X \\ *Sorumlu yazar/ Corresponding Author: Nilüfer Kablan \\ Gönderim Tarihi / Received: 15.12.2020 \\ Kabul Tarihi / Accepted: 23.02.2021 \\ DOI: $10.34087 /$ cbusbed. 841388

\section{$\ddot{O} z$}

Giriş ve Amaç: Bu çalışma uluslararası bir sivil toplum örgütü aracılığıyla Türkiye'de protez hizmeti verilen Suriye savaşı mağduru transtibial ve transfemoral amputelerin protez memnuniyetlerini değerlendirmek ve protez memnuniyetine etki eden faktörleri belirlemek amacıyla yapılmıştır.

Gereç ve Yöntemler: Araştırma Mart, 2019- Eylül, 2020 tarihleri arasında xxxx Derneği Protez merkezlerinden protez hizmeti alan Suriye Savaşı mağduru unilateral transtibial $(n=55)$ ve transfemoral $(n=56)$ amputeler üzerinde gerçekleştirilmiştir. Protezle ilişkili memnuniyet değerlendirilmesi Orthotics Prostetics Users Survey- Cihaz Memnuniyeti Modülü (OPUS-CMM) ile yapılmıştır. Verilerin analizinde tanımlayıcı istatistiksel teknikler (ortalama ve standart sapma), ikili karşılaştırmalarda Bağımsız t Test, çoklu karșılaştırmalarda Kruskal Wallis Test kullanılmıştır.

Bulgular: Amputelerin cinsiyet, amputasyon seviyesi, amputasyon yılı, amputasyon nedeni, protez kullanım süresi ve süspansiyon tipine göre oluşturan alt gruplardaki OPUS-CMM puanlarının benzer olduğu görülmüştür ( $p>0,05)$.

Sonuç: Türkiye'de yaşayan Suriyeli mülteci transtibial ve transfemoral amputelerde amputasyon seviyesi, cinsiyet, amputasyon yılı, protez kulllanım süresi ile süspansiyon tipinin protez memnuniyetini belirleyici bir etken olmadığı tespit edilmiştir.

Anahtar kelimeler: Ampute, Orthotics Prostetics Users Survey, Protez, Suriye Savaş1.

\section{Abstract}

Objective: This study was conducted to evaluate the prosthesis satisfaction of transtibial and transfemoral amputees who were victims of the Syrian war, and to determine the factors affecting prosthesis satisfaction, through an international non-governmental organization.

Materials and Methods: The research was carried out on unilateral transtibial $(n=55)$ and transfemoral $(n=56)$ amputees who were victims of the Syrian War, and who received prosthesis service from xxxx Association Prosthetic Centers between March, 2019- September, 2020. Prosthesis-related satisfaction was evaluated with the Orthotics Prostetics Users Survey-Device Satisfaction Module (OPUS-CMM). Descriptive statistical techniques (mean and standard deviation), Independent t-Test for pairwise comparisons, Kruskal Wallis Test for multiple comparisons were used in the analysis of the data.

Results: OPUS-CMM scores of amputees were found to be similar in subgroups according to gender, amputation level, amputation year, amputation reason, prosthesis usage time and suspension type $(\mathrm{p}>0.05)$. 
Conclusion: It was determined that amputation level, gender, amputation year, prosthesis usage time and suspension type were not a determining factor for prosthesis satisfaction in Syrian refugee transtibial and transfemoral amputees living in Turkey.

Keywords: Amputee, Orthotics Prostetics Users Survey, Prosthesis, Syrian war.

\begin{abstract}
Protez rehabilitasyonunda, yapılan girişimlerin sonuçlarının ölçülmesi ve değerlendirilmesi klinik uygulamaları kanıta dayalı veriler üzerinden gerçekleştirmek ve geliştirebilmek için gereklidir [1]. Yapılan tekrarlı değerlendirmeler klinisyenlere, hastanın sorunlarını zamanında tespit etme ve kaliteyi artırmak için gerekli girişimlerde bulunabilme imkânı sunmaktadır [2]. Burada önemli nokta, değerlendirmenin sadece protezin mekanik özelliklerini değil hasta tarafından nasıl algılandığını da içermesidir [3]. Proteze yönelik algının göz önünde tutulması, hastanın tedavi programına daha iyi uyum gösterebilmesi ve programın devamlılığının sağlanabilmesi için çok önemlidir [4].

Günümüz Arap coğrafyasında, amputasyon nedeni olarak diyabet birinci sırada olmasına rağmen savaşa bağlı amputasyon görülme sıklığ 1 da her geçen gün artmaktadır [5,6]. Türkiye, Suriye Savaş’1 nedeniyle çok sayıda savaş mağduru amputenin protez hizmeti aldığı bir ülke konumundadır. Savaş mağdurlarına verilen hizmet kalitesinin artırılması ve devamlılığının sağlanmasında proteze ilişkin hasta memnuniyetinin değerlendirilmesi önemlidir. $\mathrm{Bu}$ nedenle çalışmanın amacı uluslararası bir sivil toplum örgütü aracılığıyla Türkiye'de protez hizmeti verilen Suriye savaşı mağduru transtibial (TTA] ve transfemoral (TFA) amputelerin protez memnuniyetlerini değerlendirmek ve protez memnuniyetine etki eden faktörleri belirlemektir.
\end{abstract}

\section{Materials ve Methods}

Çok merkezli yapılan çalışma, uluslararası bir sivil toplum örgütü (xxxxx) bünyesinde faaliyet gösteren ve 3 ayrı bölgede (İstanbul, Şanlıurfa, Reyhanlı) kurulmuş protez-ortez merkezlerinden Mart, 2019- Eylül, 2020 tarihleri arasında protez hizmeti alan Suriye savaşı mağduru amputeler üzerinde yapılmıştır. Bu tarihlerde ilgili merkezlerde protez yapilan 469 amputeden, bilateral veya değişik seviyelerde ayak amputasyonuna sahip olanlar, üst extremite amputasyonu, kalça dezartikülasyonu ve nörolojik sebeplere bağlı ortez kullanmak zorunda olanlar amputeler $(\mathrm{n}=211)$ değerlendirmeye alınmamıştır.

Arap dilini anlayıp, cevaplayabilecek alg1 ve zihinsel yeterliliğe sahip, 18-72 yaş arası, en az 6 aydır protez kullanan 258 transtibial (TTA) ve transfemoral (TFA) amputeden çalışmaya katılmayı kabul eden 111 ampute (ort yaş:36,27 $\pm 13,04$ ) çalışmaya dahil edilmiştir. Çalışma 55 TTA (ort yaş:40,03 $\pm 13,56$ ) ve 56 TFA (ort yaş:32,57 $\pm 11,45)$ ampute ile tamamlanmıştır. Hastalar aynı hekim ve fizyoterapist tarafindan planlanan (ortalama 6-8 seans süren) benzer protez rehabilitasyonu programına dahil edilmiştir.

Çalışma için etik kurul onayı xxxxx Üniversitesi, Tıp Fakültesi, Girişimsel Olmayan Klinik Araştırmalar Etik
Kurulu'ndan (xxxx) alınmıştır. Çalışma Helsinki Deklerasyonu'na uygun olarak yürütülmüştür.

Katılımcılar çalışmanın amacı ve içeriği hakkında bilgilendirilmiştir ve her bir katılımcıdan imzalı onam alınmasını takiben verilerin toplanmasına başlanmıştır. Değerlendirme katılımcıların dikkatinin dağılmasını önlemek amacıyla, ses izolasyonu sağlanmış bir odada yapılmıştır. Katılımcılar ile iletişim ana dili arapça olan, iyi düzeyde Türkçe bilen ve protez terminolojisine hâkim bir tercüman ile sağlanmıştır. Yüzyüze görüşme ile katılımcıların demografik verileri (yaş, medeni durum, eğitim düzeyi vb.) ile amputasyon (amputasyon nedeni/yılı/seviyesi vb.), güdük (fantom hissi/ağrıs1, güdük yarası vb) ve protezle ilişkili (protez süspansiyon/eklem/ayak tipi, protez kullanım süresi vb.) tanımlayıcı verileri kaydedilmiştir.

Protezle ilişkili memnuniyet düzeyi Orthotics Prostetics Users Survey- Cihaz Memnuniyeti Modülü (OPUSCMM) Arapça versiyonu ile değerlendirilmiştir. OPUS, Heinemann ve ark. [7] tarafından ingilizce olarak geliştirilen, protez-ortez kullanıcılarını değerlendirmek amaciyla kullanılan ve hastanın kendisinin doldurduğu bir ölçüm aracıdır. Alt Ekstremite Fonksiyonel Durum, Üst Ekstremite Fonksiyonel Durum, Yaşam Sağlık Kalitesi, Hizmet Memnuniyeti, ve Cihaz Memnuniyeti olmak üzere toplam 5 modülden oluşmaktadır. Puanlandırma Likert Skalasına göre 1 (Kesinlikle Katılıyorum) ile 4 (Kesinlikle Katılmıyorum) arasında yapılmaktadır [8].

$\mathrm{Bu}$ çalışmada katılımıının OPUS-CMM modülünde bulunan ve protezin uyumu, ağırlığı, konforu, giyim kolaylığı, dayanıklığı, görüntüsü, ağrı ve irritasyon oluşturma etkisinin sorgulayan 8 soruya verdiği cevapların toplamından elde edilen puan OPUS-CMM puanı olarak kaydedilmiştir. Minumum 8 maksimum 32 puanın alındığı modülde, düşük puan protez memnuniyetinin yüksekliğini göstermektedir. OPUSCMM'nin Arapça geçerlik çalışması Baksh ve ark. [9] tarafından ortez kullanıcıları üzerinde gerçekleştirilmiştir. Modülün bu çalışmada kullanımı için Baksh ve ark.'dan gerekli izin alınmıştır.

\subsection{Istatistiksel analiz}

Örneklem büyüklüğü G*Power 3.1.7 Programı (Kiel University, Kiel, Almanya) kullanılarak hesaplanmış ve ön görülen minimum olgu sayısı her bir grup için 51 ( $80 \%$ güç, 0.5 etki büyüklüğü ve $\alpha=0.05$ Tip I hata olasılığı) olarak belirlenmiştir. $\mathrm{Bu}$ çalışmada tüm değerlendirmeler için anlamlılık seviyesi $\mathrm{p}<0,05$ olarak belirlenmiş ve istatistiksel işlemler Windows için hazırlanmış SPSS (Version 21.0. IBM Corp., Armonk, NY, USA) programında yapılmıştır. Grupları betimlemeye yönelik tanımlayıcı istatistiksel teknikler (ortalama ve standart sapma) kullanıldı. Verilerin normal dağılımı Kolmogrov-Smirnov Testi ile 
değerlendirilmiştir. İkili karşılaştırmalarda Bağımsız t Test, çoklu karşılaştırmalarda Kruskal Wallis Test kullanılmıştır.

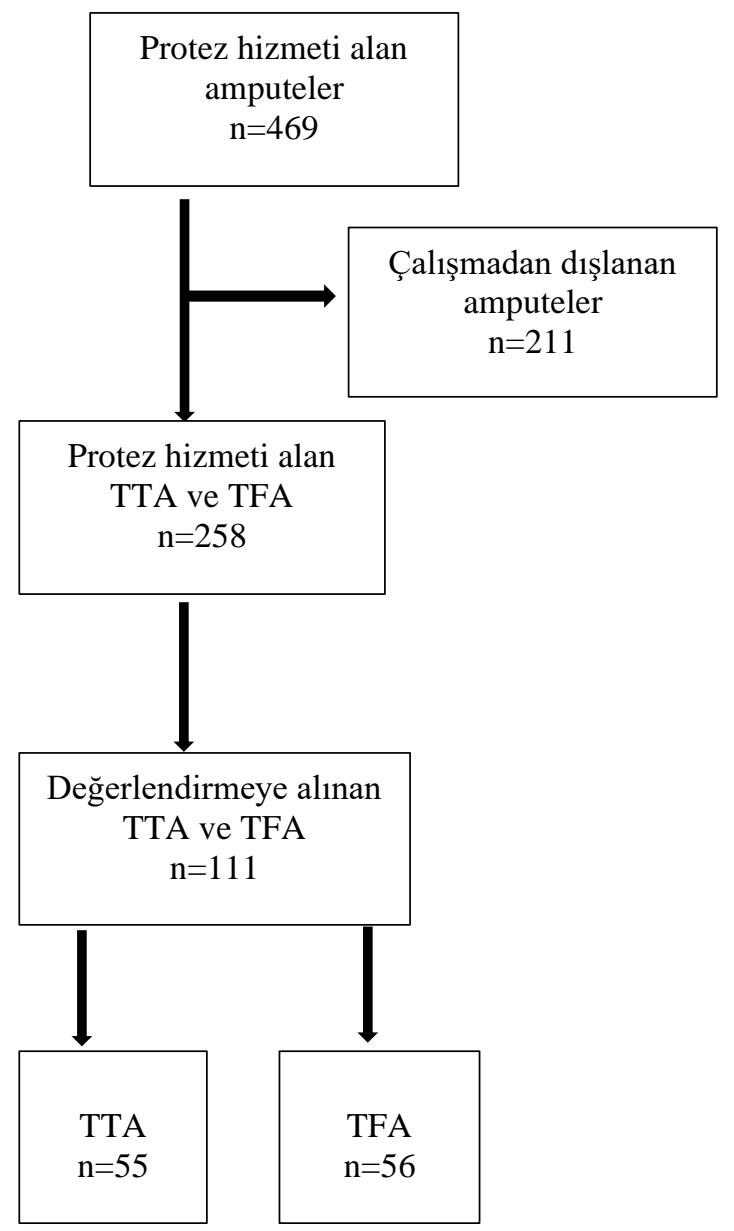

Sekil 1. Ampute olguların seçimi (TTA:Transtibial ampute, TFA: Transfemoral ampute )

\section{Bulgular ve Tartışma}

\subsection{Bulgular}

TFA grubun yaş ortalamasının TTA grubuna göre anlamlı düzeyde düşük olduğu tespit edilmiştir $(p=0,002)$. Ampute bireylerin diğer sosyo-demografik ve protez özellikleri Tablo 1 'de verilmiștir

Çalışmaya aldığımız amputelerin \% 19,8'zi fantom hissi, $\%$ 25,2'si güdük hassasiyeti, \% 9'u ise güdük yarası olduğunu beyan etmiştir.

Amputelerin genel OPUS-CMM puanı 16,21 $\pm 5,31$ (minmax;8-32) olarak tespit edilmiştir.

Amputasyon seviyesi, cinsiyet, amputasyon y1l, amputasyon nedeni, protez kullanım süresi ve süspansiyon tipine göre bireylerin OPUS-CMM puanlarında istatistiksel bir fark gözlemlenmemiştir (p>0,05) (Tablo 2).

\subsection{Tartışma}

Türkiye'de sığınmacı olarak barındırılan Suriye Savaş'1 mağduru unilateral transtibial ve transfemoral amputelerde protez memnuniyetini değerlendirmek ve
Tablo 1. Amputelerin sosyo-demografik ve protez ile ilișkili özellikleri

\begin{tabular}{|c|c|c|}
\hline \multicolumn{2}{|c|}{ Demografik Özellikler } & \multirow{2}{*}{$\begin{array}{c}\text { n }(\%) \\
29(26,1)\end{array}$} \\
\hline & Bekar & \\
\hline Medenı Durum & Evli & $82(73,9)$ \\
\hline \multirow{4}{*}{ Eğitim Düzeyi } & Okur-Yazar Değil & $11(9,9)$ \\
\hline & İlköğretim & $29(26,1)$ \\
\hline & Ortaöğretim & $61(55,0)$ \\
\hline & Üniversite & $10(9,0)$ \\
\hline \multirow{3}{*}{ İş Durumu } & İşsiz & $80(72,1)$ \\
\hline & Öğrenci & $6(5,4)$ \\
\hline & Çalışan & $25(22,5)$ \\
\hline \multirow{4}{*}{ Diz Tipi (TFA'de) } & $\begin{array}{l}\text { Mnsent-Mekn } \\
\text { Diz }\end{array}$ & $18(32,1)$ \\
\hline & Pnömatik & $27(48,2)$ \\
\hline & Hidrolik & $10(17,9)$ \\
\hline & Mikroişlemcili & $1(1,8)$ \\
\hline \multirow{4}{*}{ Ayak Tipi } & Sach & $9(8,1)$ \\
\hline & Dinamik & $34(30,6)$ \\
\hline & Mafsal & $53(47,7)$ \\
\hline & Karbon & $15(13,5)$ \\
\hline
\end{tabular}

Mnsent-Mekn: Monosentrik-Mekanik;

protez memnuniyetine etki eden faktörleri belirlemek amacıyla yapılan çalışmada, genel olarak protez memnuniyetinin iyi düzeyde olduğu, amputasyon ve protez ile ilişkili özellikler açısından da farklılık göstermediği tespit edilmiştir.

Alt ekstremite amputeleri, günlük yaşam aktivitelerini sürdürebilmek için çoğunlukla proteze bağımlıdır. Bu nedenle, protezden duyulan memnuniyet, ambulasyonun yeniden kazanılmasında anahtar rol oynar ve protez kullanımının optimize edilmesi, reddinin önlenmesi ve rehabilitasyona uyumun sağlanması için oldukça önemlidir. Protezden kaynaklı memnuniyetsizlikler sebebiyle protez kullanımının bırakılması istenilmeyen bir durumdur [10]. Bu doğrultuda memnuniyetsizliği ve ilişkili olduğu faktörleri saptamak gerekmektedir. Memnuniyet nicelleştirilmesi oldukça zor bir kavramdır. Protezin kullanım konforu, kolaylığı, kozmetik yeterliliği, dayanıklılığı ve rahatlığı gibi faktörlerin yanı sıra; amputelerin protezden beklentilerinin sağlık profesyonelleri ve merkezler tarafindan ne kadar iyi karşılandığı da memnuniyet düzeyini ilgilendiren faktörlerdendir [10-12].

Elde ettiğimiz bulgular değerlendirilen amputelerin genel protez memnuniyetinin iyi düzeyde olduğunu göstermektedir. Araştırma bünyesinde değerlendirilen 
Tablo 2. Amputelerin alt grup özelliklerine göre OPUS-CMM puanları.

\begin{tabular}{|c|c|c|c|c|}
\hline \multicolumn{2}{|c|}{ Alt Gruplar } & \multirow{2}{*}{$\begin{array}{c}\mathbf{n}(\%) \\
12(10,8)\end{array}$} & \multirow{2}{*}{$\begin{array}{c}\begin{array}{c}\text { OPUS-CMM } \\
\text { Ort } \pm \text { SS }\end{array} \\
16,83 \pm 7,18\end{array}$} & $\mathbf{p}$ \\
\hline & Kadın & & & \multirow{2}{*}{$0,751^{*}$} \\
\hline & Erkek & $99(89,2)$ & $16,14 \pm 5,08$ & \\
\hline \multirow{2}{*}{$\begin{array}{l}\text { Amputasyon } \\
\text { Seviyesi }\end{array}$} & Transtibial & $55(49,5)$ & $15,89 \pm 5,45$ & \multirow{2}{*}{$0,525^{*}$} \\
\hline & Transfemoral & $56(50,5)$ & $16,53 \pm 5,20$ & \\
\hline \multirow{3}{*}{ Amputasyon Yilı } & $2015-2020$ aras 1 & $65(58,6)$ & $16,03 \pm 5,18$ & \multirow{3}{*}{$0,522 * *$} \\
\hline & $2010-2015$ aras 1 & $37(33,3)$ & $16,10 \pm 5,58$ & \\
\hline & 2010 öncesi & $9(8,1)$ & $18,00 \pm 5,40$ & \\
\hline \multirow{3}{*}{$\begin{array}{l}\text { Amputasyon } \\
\text { Sebebi }\end{array}$} & Kaza & $12(10,8)$ & $16,58 \pm 6,17$ & \multirow{3}{*}{$0,818 * *$} \\
\hline & Savaş & $83(74,8)$ & $16,33 \pm 5,04$ & \\
\hline & Kronik Hastalık & $16(14,4)$ & $15,31 \pm 6,24$ & \\
\hline \multirow{2}{*}{$\begin{array}{l}\text { Protez Kullanım } \\
\text { Süresi }\end{array}$} & $<1 Y_{1} 1$ & $48(43,2)$ & $16,02 \pm 5,40$ & \multirow{2}{*}{$0,737^{*}$} \\
\hline & $\geq 1 Y_{1 l}$ & $63(56,8)$ & $16,36 \pm 5,28$ & \\
\hline \multirow{2}{*}{ Süspansiyon Tipi } & Aktif/Distal/Pasif/P. Vent & $19(17,1)$ & $17,73 \pm 4,60$ & \multirow{2}{*}{$0,172^{*}$} \\
\hline & Shuttle Lock & $92(82,9)$ & $15,90 \pm 5,42$ & \\
\hline
\end{tabular}

P. Vent: Pasif Venti; *Bağımsız t Test; **Kruskal Wallis Test; $\mathrm{p}<0.05$

Suriye'li mülteci amputelere protez ve rehabilitasyon hizmeti benzer bir program çerçevesinde ve aynı ekibin (hekim-fizyoterapist) kontrolü altında sağlanmıştır. Bu sayede protez memnuniyetini etkileyecek farklı servis hizmetlerinin etkisi büyük oranda devre diş1 bırakıldığından, elde edilen ortalama OPUS-CMM puanlarının sadece protez ve amputasyon ile ilişkili özelliklerden kaynaklandığı sonucuna ulaşılabilir.

Araştırma bulgularımız bütüncül olarak ele alındığında; protez memnuniyetinin cinsiyete göre anlamlı düzeyde farklılık göstermediği tespit edilmiştir. Murray ve ark., çalışmalarında demografik özellikler ile protez memnuniyeti arasında ilişkiye çalışmamıza benzer şekilde rastlamamıştır [13]. Geertzen ve ark., yaptıkları çalışmada, cinsiyetin protez memnuniyetiyle anlamlı ilişkisi olmadığını bildirmiştir [12]. Bulgularımız geçmiş çalışmalardan elde edilen bulgularla uyumlu olsa da, araştırmamızda kadın olgu sayısınıın kısıtlayıcı unsur olduğu gözönünde tutulmalıdır.

$\mathrm{Bu}$ çalışmada protez memnuniyeti açısından her iki amputasyon seviyesindeki olguların benzer memnuniyet düzeyine sahip oldukları tespit edilmiştir. Bizim çalışmamızın aksine, protez memnuniyetinin amputasyon seviyesinden etkilendiğini gösteren çalışmalar da mevcuttur [14,15]. Amputasyon seviyesi yükseldikçe, protezin işlev ve ağırlığı ile ilişkili olarak memnuniyet düzeyinin düştüğü bildirilmiştir [16]. Çalışmamızda yer alan TFA grubun, TTA gruba göre 
daha genç bireylerden oluşması, amputasyon seviyesi yüksekliğinin protez memnuniyeti üzerine olumsuz etkisini azaltmış olabilir. Bununla birlikte yaş unsurunun doğuracağ 1 beklentilerin değerlendirmeye yansımasının olmaması da bu çalışmanın kısıtlılığıdır

Diğer taraftan savaş kaynaklı amputasyonlarda görülen tibial kırıkların parçalı ve tamirinin zor olması, yumuşak doku yetersizliğinden kaynaklanan güdük hassasiyeti ve güdük yara oranlarının TTA gruplarda TFA grubuna nazaran fazla olması amputasyon seviyesinin memnuniyet ile ilişkisine etki edecek bir başka faktör olarak öngörülmektedir [17]. Çalışmamızda TTA grupta 8 , TFA grupta ise 2 olmak üzere sadece 10 amputede güdük yarası olduğu tespit edilmiştir. TTA'de güdük yarası görülme oranının TFA gruba göre yüksek olması geçmiş çalışmalarla. uyumlu olmakla birlikte, tüm örneklem grubu içinde düşük oranda olması, bu çalışmada güdük yarasının amputasyon seviyesine göre protez memnuniyeti üzerinde fark oluşturacak bir etkiye sahip olmadığını düşündürmektedir.

Protez kullanımının ilk yılı, protez kullanım alışkanlığının yerleşmemesinden dolayı, protezin kendisinden çok güdük-soket uyumuna ilişkin sorunların sık görüldüğü bir dönemdir [18]. Diğer taraftan daha uzun süre protez kullananlarda tecrübenin artması ile birlikte protezden beklentileri yükselmektedir [13]. Bu çalışmada protez memnuniyetinin amputasyon yılına bağlı olarak anlamlı düzeyde değișmediği görülmektedir. Katılımcıların \%58,9'unda amputasyon yılı olarak son 5 yıllık period işaret edilirken, amputelerin \%96,5'sının protez kullanım süresinin 5 yılın altında olduğu tespit edilmiştir. Bu sonuç azımsanmayacak sayıda amputenin protez hizmetine amputasyonu takiben hemen ulaşamadığını göstermektedir. Buna ek olarak, katılımcıların savaş mağduru amputelerden oluşması ve mülteci amputelerin içerisinde bulunduğu yaşam koşulları göz önüne alındığında protezden beklentinin düşük olduğu şeklinde yorumlanabilir.

Çalışmalarda, hem TTA hemde TFA gruplarda, travmatik kökenli amputelerin protez ile ilgili memnuniyetlerinin vasküler kaynaklı amputelere göre daha yüksek olduğu gösterilmiştir [19]. Bu çalışmada amputelerin \%74,1'nde savaş kaynaklı amputasyonun olması ve kronik hastalık kaynaklı amputasyon sayısının düşüklüğü, amputasyon sebebinin protez memnuniyeti üzerine etkisini tespit etmede kısıtlayıcı bir faktör olarak düşünülebilir.

Üst ekstremite amputasyonlarından farklı olarak alt ekstremitede güdüğe doğrudan ağırlık aktarımı olduğundan protezin yük altındaki stabilitesi, güdük ile uyumu ve süspansiyonu çok önemlidir [20]. Protez komponentlerinin, soket yerleşiminin ve süspansiyon sisteminin protez memnuniyetini doğrudan etkilediği kabul edilmektedir [21]. Bulgularımızda TTA grupta daha fazla olmak üzere her iki grupta da süspansiyon tipi olarak genellikle shuttle lock'un tercih edildiği görülmektedir. Berke ve ark., Vietnam gazilerinde yaptıkları çalışmada azalmış protez memnuniyetini zayıf soket süspansiyonu, kötü protez uyumu, onarım gerekiliği ve protez değiştirme zorluğu ile ilişkilendirmiştir [22]. Bu çalışmada Berke ve ark.'nın görüşlerine paralel olarak, amputelerin en güncel süspansiyon sistemlerine erişebilmeleri, ücretsiz ve sürekli kontrollerle takip edilmeleri ve rehabilitasyon süreçlerinin yer alması, gerektiğinde yenileme haklarının olması memnuniyet açısından davranışlarını olumlu etkilemiş olabileceği düşünülmektedir. Aynı şekilde çalışmamızda yer alan amputelerin tamamının aynı protez ve hizmet kalitesi altında aynı uzmanlar tarafından değerlendirilip takip edilmesinin proteze ilişkin özelliklere göre oluşturduğumuz alt grupların protez memnuniyetlerinin anlamlı farklılık göstermemesini sağladığı düşünülmektedir.

Çalışmamızın sınırlılıkları; bazı alt grupların sayıca homojen dağılmaması dolayısıyla ikili karşılaştırmaların yeterince yapılamaması, Suriye'de ikamet eden ve aynı organizasyondan hizmet alan amputelerin değerlendirmelerinin bu çalışmada yer almamasıdır.

\section{Sonuç}

Sonuç olarak, amputasyon ve protez ile ilgili alt gruplarda protez memnuniyetinin değerlendirildiği bu çalışmada, tüm alt grup OPUS-CMM puan ortalamalarının benzer olduğu ve iyi düzeyde protez memnuniyetine işaret ettiği görülmektedir. Sınırlılıklarımıza rağmen mevcut sonuçlarımız bu alanda yapılacak olan iyileştirme çabalarını yönlendirmeye yardımcı olacaktır. Türkiye'de yaşayan sığınmacı amputelerde protez memnuniyetine ilișkin faktörleri ortaya koymak için alt grup sayılarının yeterli olduğu, büyük ölçekli ve çok merkezli planlanan daha fazla çalışmanın yapılmasına ihtiyaç vardır.

\section{Teşekkür ve Bilgilendirme}

Uluslararası Doktorlar Derneğine (www.aidoctors.org) ve data toplama sürecine katkılarından dolay1 fizyoterapist Zehra Akpınar'a teşekkür ederiz.

\section{References}

1.Hill, W, Kyberd, P, Hermansson, L.N, Hubbard, S, Stavdahl, Ø, Swanson, S, Upper Limb Prosthetic Outcome Measures (ULPOM):

A Working Group and Their Findings Wendy, Prosthetics and Orthotics International, 2009, 21(9), 69-82.

2. Heinemann, A.W, Connelly, L, Ehrlich-Jones, L, Fatone, S, Outcome instruments for prosthetics: Clinical applications. Physical medicine and rehabilitation clinics of North America, 2014, 25(1), 179-98.

3. Jarl, G.M, Maria, L, Hermansson, N. Translation and linguistic validation of the Swedish version of Orthotics and Prosthetics Users' Survey, Prosthetics and Orthotics International, 2009, 33(4), 329 38 
4. DeRuyter, F. The importance of outcome measures for assistive technology service delivery systems, Technology and Disability, 1997, 6(1), 89-104

5. Yaghi, K, Yaghi, Y, McDonald, A.A, Yadegarfar, G, Cecil, E, Seidl, J, Dubois, E, Rawaf, S, Majeed, A, Diabetes or war? Incidence of and indications for limb amputation in Lebanon, 2007, EMHJ-Eastern Mediterranean Health Journal, 2012, 18 (12), 1178-1186.

6. Şişli, E, Kavala, A.A, Mavi, M, Sarıosmanoğlu, ON, Oto, Ö. Single centre experience of combat-related vascular injury in victims of Syrian conflict: Retrospective evaluation of risk factors associated with amputation, Injury, 2016, 47(9), 1945-50.

7. Heinemann, A.W, Bode, R.K, O'Reilly, C.O, Development and Measurement Properties of the Orthotics and Prosthetics Users' Survey (OPUS): A Comprehensive Set of Clinical Outcome Instruments, Prosthetics and Orthotics International, 2003, 27, 191206.

8. Jarl, G.M, Heinemann, A.W, Norling Hermansson, L.M, Validity evidence for a modified version of the Orthotics and Prosthetics Users' Survey, Disability and Rehabilitation. Assistive Technology, 2012, 7(6), 469-78.

9. Bakhsh, H, Franchignoni, F, Bravini, E, Ferriero, G, Giordano, A, Foti, C, Validation of the Arabic version of the client satisfaction with device module of the "orthotics and prosthetics users" survey, Annals of Saudi Medicine, 2014, 34(4), 320-7.

10. Peaco, A, Halsne, E, Hafner, B.J, Assessing satisfaction with orthotic devices and services: a systematic literature review, JPO: Journal of Prosthetics and Orthotics, 2011, 23(2), 95-105.

11. Bosmans, J, Geertzen, J, Dijkstra, PU, Consumer satisfaction with the services of prosthetics and orthotics facilities, Prosthetics and Orthotics International, 2009, 33, 69-77.

12. Geertzen, J.H, Gankema, H.G, Groothoff, J.W, Dijkstra, P.U, Consumer satisfaction in prosthetics and orthotics facilities, Prosthetics and Orthotics International, 2002, 26, 64-71.

13. Murray, C.D, Fox, J, Body image and prosthesis satisfaction in the lower limb amputee, Disability and rehabilitation, 2002, 24(17), 925-931.

14. Webster, J.B, Hakimi, K.N, Williams, R.M, et al, Prosthetic fitting, use, and satisfaction following lower-limb amputation: a prospective study, Journal of rehabilitation research and development, 2012, 49 1493-504.

15. Samitier, C.B, Guirao, L, Costea, M, et al., The benefits of using a vacuum- assisted socket system to improve balance and gait in elderly transtibial amputees, Prosthetics and orthotics international, 2016, 40, 83-8.

16. Pascore, C.G. Patient satisfaction in primary health care: A literature review and analysis, Evaluation and program planning, 1983, 6(34), 185-210.

17. Ali, S, Osman, N.A.A, Eshraghi, A, Gholizadeh, H, Razak, N.A.B.A Abas, W.A.B.B.W. Interface pressure in transtibial socket during ascent and descent on stairs and its effect on patient satisfaction, Clinical Biomechanics, 2013, 994-8.

18. Sanders, J.E, Harrison, D.S, Allyn, K.J, Myers, T.R, Clinical utility of in-socket residual limb volume change measurement: Case study results, Prosthetics and Orthotics International, 2009, 33(4), 378-90.

19. Hafner, B.J, Amtmann, D, Abrahamson, D.C, Morgan, S.J, Kajlich, A.J, Salem, R, Normative PEQ-MS and ABC scores with lower limb loss, Proceedings of the American Academy of Orthotists \& Prosthetists (AAOP) 39th Academy Annual Meeting and Scientific Symposium, February 20-23, 2013, Orlando, FL.

20. Raichle, K.A, Hanley, M.A, Molton, I, et al., Prosthesis use in persons with lower- and upper-limb amputation, Journal of rehabilitation research and development, 2008, 45(7), 961-72.

21. Ali, S, Abu Osman, N.A, Naqshbandi, M.M, et al. Qualitative study of prosthetic suspension systems on transtibial amputees' satisfaction and perceived problems with their prosthetic devices. Archives of physical medicine and rehabilitation, 2012, 93, 1919-23.

22. Berke, G.M, Fergason, J, Milani, J.R, et al., Comparison of satisfaction with current prosthetic care in veterans and service members from Vietnam and OIF/OEF conflicts with major traumatic limb loss, Journal of rehabilitation research and development, 2010 , 47, 361-71. http://edergi.cbu.edu.tr/ojs/index.php/cbusbed isimli yazarın CBU-SBED başlıklı eseri bu Creative Commons Alıntı-Gayriticari4.0 Uluslararası Lisansı ile lisanslanmıştır.

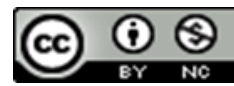

